\title{
INNOVATION IN A PODSHELL: BRINGING INFORMATION LITERACY INTO THE WORLD OF PODCASTING
}

Jody Atkinson, Jaya Berk, Joanne Comerford and Sonja Olsen

\begin{abstract}
:
Podcasting is creating a buzz in the world of information and communication technologies. Since Adam Curry and Dave Winer released their iPodder software in September 2004, podcasting has been embraced by mainstream media such as ABC Radio and CNN News. Incorporating the use of Really Simple Syndication (RSS), podcasting involves the downloading of an audio program to a computer, portable digital player such as an ipod or a mobile phone. Podcasting is being used by academics as an alternative to lectures in classrooms, in advertising and marketing and in the entertainment industry. Why not in libraries?

Curtin University of Technology prides itself on its culture of innovation and willingness to investigate and adapt new technologies. The Curtin University Library and Information Service applies this innovative approach to our information service provision. Following the successful implementation of our SMS a Query service, we saw the potential for offering information literacy to our students through the use of podcasts.
\end{abstract}

Our initial 'Five tips on...' series covers many aspects of information literacy such as Referencing, EndNote, and Library Databases. Released at regular intervals throughout the semester these podcasts are an accessible, portable and convenient mode of communication which enables our timepoor millennial students to download and play them at their own convenience.

This paper examines the development of a pilot program for using podcasting as a tool in the provision of information literacy in an academic library. We will examine the implementation process and the issues we encountered in developing our podcasting series.

The Curtin Library and Information Service (LIS) has always taken an innovative approach to its service provision and strives to lead in the use of ubiquitous technology to provide alternative learning opportunities. For example in 2004 the SMS a Query service was successfully implemented and has provided students with a quick and easy method of communicating with the library. Following on from this the potential for using podcasts to deliver information literacy in a new and exciting way was recognised by LIS staff. Soon after a pilot program was developed for using podcasting as a tool in the provision of information literacy in an academic library environment.

\section{So what is podcasting and who is using it?}

For those who are unfamiliar with the term, Encyclopaedia Britannica Online defines podcasting as:

"a new audio genre... Named after the iPod portable media player but not restricted to it, podcasting was essentially a system for posting a 
file with audio content onto the World Wide Web and for providing an automatic online notification to the computer of a subscriber to download the file." (Media and Publishing, 2006).

Adam Curry and Dave Winer are recognised as the creative force behind podcasting. They developed specialised software tools including 'iPodder', which was released in 2004 (Gordan-Murnane, 2005). Podcatching software, such as iPodder or iTunes, and the use of Really Simple Syndication (RSS) feeds is what makes podcasts different and more attractive than its precursor 'audioblogging'. This means that, once subscribed to, the latest podcast issues can be automatically downloaded to any MP3 player when it is connected to a computer. Podcasts can then be played and replayed, anywhere, anytime and as often as required. It is this liberation from the computer desk and tracking of personal programs that adds so much value to the podcast.

So who's using podcasts? The literature suggests that the majority of use lies in the student population; 'Demographically those who are downloading podcasts are in the same age bracket as many college or university students' (DeVoe, 2006, p.78). In March 2005, Rainie and Madden's survey found that almost one in five 18-28 year olds in America own a MP3 player and half of these have downloaded podcasts. Since University students traditionally fall into this age bracket, these figures can provide a snapshot of student use of MP3 players and podcasts in America.

Whilst we do not know the figures of ownership and use here in Australia, there is no reason to suggest that the numbers would not be similar. Historically, Australians are eager to embrace new technologies, seen in the rapid uptake of, mobile phones for example or, computers and internet use. Australian Bureau of Statistics (ABS) figures show the number of households with access to a mobile phone rose from 44\% in 1998 to $72 \%$ in 2002 (Australian Bureau of Statistics, 2003). Similarly, the ABS reports that non dial-up subscribers to the Internet rose by 109\% in the period between March 2004 and March 2005 (Australian Bureau of Statistics, 2005).

So, who is producing podcasts as a communication tool? There are thousands of podcast sites accessible via the web. They range in sophistication from the truly terrible classroom conversations, complete with background noise and often varied levels of audio clarity, to the more professional offerings of the $A B C$ 's national radio programs.

Numerous universities in the United States have taken advantage of the ease of production and use of podcasts. Course lectures can be reviewed and tutorial discussions can be recorded and aired. In September 2004 Duke University distributed ipods preloaded with orientation materials to their first year students whilst at Arizona State, the University President regularly podcasts on local student concerns (Lum, 2006). A number of well respected institutions, including Brown, Duke and Stanford Universities have joined with Apple Computer to test the production of podcasts of course materials (DeVoe, 2006) indicating the current adoption of this new technology into the teaching and learning process. 
In the higher education sector in Australia, a number of developments indicate the increasing popularity and usefulness of the podcast. Sites such as those at Griffith University and the University of Sydney produce podcasts covering University news, events and public lectures by prominent speakers such as Kim Beazley and Robert Fisk. The University of Newcastle provides podcasts aimed at the student population with topics as varied as health issues and the latest technology.

An environmental scan showed that podcasts have not yet been as readily embraced by libraries either internationally or in Australia. There have been early developments by public libraries who are starting to use podcasts to advertise library news, market services to library patrons and develop audio books (Gordan-Murnane, 2005). However, there is little innovative use as yet from University libraries. For this reason Curtin (LIS) saw an opportunity to use podcasts to bring information literacy into the life of today's learner and took up the challenge.

\section{How did we know that our students would use our podcasts and what made us think this could work?}

Curtin University of Technology has a total student population of over 39,500 students. Of this number $24 \%$ are international onshore students and approximately 2,600 students study externally (Curtin University of Technology, 2006, data from 2005). Therefore we saw that we had, potentially, a large target market. We believed that our external students could benefit from our podcasting series by being able to access library information presented by library staff without having to physically come to the library, an impossibility for most remote students. We also recognised how the ability of podcasts to be replayed over and over again would be beneficial to our international students including the ESL (English as a Second Language) students, allowing them to process the information at their own pace. In fact it was seen that all Curtin students could benefit from being able to access library information in the form of podcasts.

We had to consider what we knew about these students to target our podcasts to their needs. Primarily we knew that this generation can multi-task and are not techno-phobic having grown up with a large variety and range of different information communication technologies:

"An ever increasing number of students consist of the so-called

'Millennials': today's teenagers and twentysomethings who are the first generation to grow up fully wired and technologically fluent.

Blogs, iPods, instant messaging, social networking technologies, and portable electronic devices are seamlessly woven into their daily lives. These students will have different requirements and expectations of libraries than their predecessors" (M.A Hansen, email discussion list, January 12, 2006).

This generation has changed the way libraries need to deliver information as we have to contend with divided attention spans. We recognised that podcasts give libraries one answer. 
During these investigations we considered different learning styles and saw how podcasting can be a useful learning tool especially for the auditory learner. The auditory learner responds or learns best from audio stimuli such as lectures or discussion (Krätzig \& Arbuthnott, 2006). Although listening has not been highly valued as a learning method by some in the educational field, it cannot be discounted as a complementary tool to more traditional methods. When teamed with other support material such as print or online guides and face to face classes it can be a valuable addition to the learning process and provide an opportunity for the auditory learner to access information in their preferred learning style (Chan \& Lee, 2005). Campbell (2005) also highlights the importance of the explaining voice in providing understanding and meaning in the learning process. However for audio to be a truly effective learning tool recordings should be kept relatively short and the information in the podcasts themselves should not be too complex (Chan \& Lee, 2005).

Whilst conducting our research we identified many other advantages of this new technology. First and foremost, in today's information environment, people want information on demand and allocating time to find information has always been hard, especially for University students with conflicting study schedules, employment demands and social pressures. Life always seems to get in the way. Podcasts are therefore invaluable to today's 'time poor' students because they allow better use of time in a hectic day. These new technological tools make it easier for students to devote time to learn as they can receive this information whilst doing something else, adding value to what is otherwise 'dead time'. Whether the student is commuting, exercising, eating or relaxing, the simultaneous use of a podcast is usually possible. 'Part of the appeal of podcasts is that users can listen to these audio files whenever they want, wherever they want, as often as they want and on the device of their choice' (DeVoe, 2006, p.78). Podcasts allow choice and enable users to be in control of what they invest their time in.

A further appeal about podcasts is their portability due to the compact size of MP3 players, leading to their easy adaption into hectic lifestyles. MP3 players are relatively cheap, increasing their use and realistically enabling students to use these as a supplement to University studies and quality of life. They are also very easy to use with little technical knowledge required and minimal 'techno-frustration', leading to podcasts fast becoming the language which today's students understand and chose to use. This is largely due to the appeal podcasts have to the youth who get easily seduced by technology and downloads.

Essentially we recognised that podcasting could be incorporated into the lives of our students because this is a new trend and trends play an important role in the successful dissemination of knowledge.

\section{What our parameters were and why we chose them}

We identified our target audience as first year Undergraduate students and we aimed the pilot at their information literacy needs. It was decided that these podcasts should tackle topics which would assist first year students who were 
new to University and provide information that would be of benefit and of interest to this target group. We saw podcasts as a way of reinforcing orientation information which students may have picked up earlier as well as reviewing and clarifying information already provided by the library.

The aim of the format of our podcasts was to make each one short and concise. For this reason a lot of time and emphasis was placed on the actual scripting of each podcast to ensure they met this criteria. We were aware of the current competition in the professional broadcasting arena, such as Radio National's slick podcast presentations and, although we knew we could not create podcasts of the same quality, we aimed to make ours as interesting, informative and professional as possible.

One of the aims of the pilot was to develop a new podcast community with students getting hooked to each week's instalment. We planned to do this by making our podcasts funky, stylish and trendy. By doing so we hoped to challenge the library stereotype and demonstrate a lively library life. We did this by using different library staff to record each podcast. This created a welcoming environment at Curtin LIS and presented a personal face to the library. We then incorporated music to the start and end of each production and presented our podcasts in a 'radio show' format, creating a catchy and captivating product.

Each podcast was created to be no more than five minutes long, firstly to enable the information to be easily absorbed by the listener and secondly to ensure the file size of each one remained relatively small to reduce download difficulties. We understood that there would be a trade-off between quality and file size, however we were aware that our focus audience of first year undergraduate students may not be able to afford expensive bandwidth and exceeding limits can cause problems and frustrations for users.

We started by creating a 'tip per week' series, with one podcast released every week. Each podcast gives the listener just enough information to catch their interest, finishing with an invitation to go to the library website for more information. Our podcasting series was seen as a complementary tool for our current information literacy programs. We set out to help demystify the library and make it a friendly, approachable place where students could come for more information once they got a 'taste' from our podcasts. We started the semester with podcasts covering introductory information that new students need to know straight away, including an audio tour of our main library building, why they need their Curtin ID number and password, and information about borrowing. Later in the semester we focused more on detailed information students might need to complete their assignments, such as what is a journal article and how to find it, and useful tips about referencing and EndNote. Our complete podcasting series can be viewed in appendix 1.

\section{The 'how to' of creating a podcasting series}

The most attractive thing about podcasting is how easy it is. It is something that anyone can do with equipment you probably already have, with software you can download for free and with a small amount of instruction which you can get 
from a simple Google search. The following is a summary of each step we undertook in the technical process to create our podcasting series:

\section{Equipment}

Investigating the technical creation of podcasts was a fairly easy process with plenty of instructions available on the web. To create our podcasts all we needed was a computer, a microphone, audio software, music (and the copyright permission to use it), a webpage on which to publish them, a podcast feed and a quiet place to record.

We chose to record onto a laptop, mostly for portability reasons. The staff areas at Curtin LIS are open-plan, so we needed to be able to move around and record where we were comfortable and not likely to be interrupted. Surprisingly, finding a quiet recording space was one of the most difficult challenges we faced. Most office space is loud with air conditioner rumbles and equipment hums. Curtin LIS was also undergoing renovations at the time, so we had some construction noise to contend with. After trying out various locations we chose to use the audio-visual viewing room in the library as our recording area as it had some soundproofing and acoustic dampening on the walls. After recording, we copied the sound files across to our network, so we could edit and mix them at our own workstations.

After various investigations we chose to use a standard computer microphone rather than a higher quality, more expensive one. We initially hoped to use a headset microphone; so that the person reading didn't have to think about where the microphone was once the levels were set, however upon investigations of professional quality microphones we came across a significant problem with compatibility. This was due to plugging a "balanced" microphone into an "unbalanced" sound card within the PC which created a hum. We found that once the sound files had been converted to MP3 files and were downloaded onto an iPod, the difference in quality between a good microphone and a cheap one was minimal. We did however encounter some quality issues with the cheaper microphone. Firstly, more attention had to be paid to setting the sound levels properly and staying a consistent distance from the microphone. We found the recording levels varied quite dramatically if the reader moved a little closer or further away during each recording. This is less of a problem with better quality microphones. Secondly, cheap microphones are more inclined to 'pop', which is an audible distortion on hard consonants like 'p's. We reduced this problem by turning the microphone on an angle during recording and by using an iPod earbud cover as a make-shift pop-sock, which worked very well.

\section{Software}

The Curtin LIS Information Technology department recommended using the audio software 'Audacity'. Reasons for using this was its ease of use and its functionality, proving it could do everything we needed and more. An added benefit was that there was no cost to the library, as it was freely available to download from the web. The only issue we came across when using this software was we did not find it very intuitive, taking us a little while to find all the functions we wanted. 


\section{Legal Issues}

With any form of broadcasting the legal issues must be considered. We found on online podcasting legal guide which was useful to this process. This can be located at: http://wiki.creativecommons.org/Podcasting_Legal_Guide. The main legal issue we needed to consider with our podcasting series was to ensure we complied with copyright legislation when using our theme music. Because we did not have the time or the resources to write our own music we had to use a piece of music from somewhere else. One option available to us was to use music under a Creative Commons licence. Creative Commons licensed material is made available by the copyright owner, which is usually the creator. These licences usually specify that the material can be used for noncommercial purposes as long as the creator is given credit. Sometimes they have additional conditions such as the piece has to be used in its entirety or can only be used for sampling. More information can be found at:

http://creativecommons.org/. There are a number of Creative Commons music sites on the web where music is available for download and use under these conditions. After investigating our options and trying out different music genres, we chose music from the Creative Commons music site called CCMixter, available at: http://ccmixter.org/. The style of music we chose was 'chill out' to assist in achieving our goal of creating funky and trendy podcasts which will appeal to our student population. Complying with the Creative Commons licence requirements we included a credit to the composer at the end of each podcast.

\section{The RSS Feed}

One of the biggest selling points of podcasts is the ability to create RSS feeds enabling new issues to be automatically downloaded to an MP3 player, reducing spam and increasing effectiveness and use. Basically, a podcast feed is an RSS feed with a few extra tags. To create one you need to use RSS version 2.0, and you use an "enclosure" tag for the MP3 file. Although there are RSS generators available on the web which can create RSS feeds on your behalf we were not able to find one that could create a podcast feed in time for the start of our pilot. With time running short, we decided to create the feed ourselves. We did not find this process particularly difficult, demonstrated by the fact that we didn't know XML but were able to implement it. We were able to utilize the RSS feed already used for our Library Blog, modifying the details and adding in the enclosure tags to adapt it for the podcast feed. The advantage of creating our own feed is that we know how the code works, and so if something were to go wrong, we have a better understanding of how to fix it.

\section{Promotion}

To promote our podcasting series we created a podcast page on the library website. In an effort to make this page more visible to students we placed links to it from a number of places including our newly created online 'Survival Guide' aimed at new students. The podcasts were also promoted through news entries on the Library News and Library Blog. The usage statistics for the podcasts have shown a steady increase over the course of the semester from approximately 100 downloads of the audiofiles in February to over 600 
downloads in April. A complete overview of our usage statistics can be viewed in appendix 2.

In May we started running a competition to further promote the pilot, where we asked clients to suggest topics for further podcasts. We offered 5 prizes of $\$ 20$ iTunes cards for the best suggestions. We created a graphic on our homepage to promote the competition and increase visibility and responses. Although we only received 11 suggestions from students there was a significant increase in usage of our podcasts during this time with more downloads in the first half of May, than in the whole of April.

\section{Cost and Staffing Implications}

Podcasting is a relatively inexpensive medium. The equipment and software required were generally items the library already had access to, or could obtain cheaply or in some cases for free. The main investment was in staff time spent working out the finer details of the content of the podcasts and technical aspects of the project. We also ensured that several staff members were able to record and create a podcast in order to provide back-up support. However once the parameters and technical issues were clarified, recording and producing the podcasts was not particularly time consuming and this part of the project was quite quick. It soon became apparent how quick and easy it was to create and release each one. This fast turnaround is part of the strong appeal of using this technology.

In summary we believe that using this new and popular distribution method to deliver varied content and themes will assist in keeping our students connected with the library environment and with information. We found the process of creating a podcasting series to be an enjoyable and rewarding experience and we were inspired by being involved in such a new and recent development, one which may set the way for future innovations. We now look to the future where we hope to include more library staff in the scripting and recording process so as new knowledge and experiences can be brought to the series. We look forward to our podcasts growing, as the library grows, and to seeing our podcast community take shape. In essence our podcasting pilot has uncovered the success of bringing information literacy into the world of podcasting, delivering innovation in a podshell. 


\section{References}

Australian Bureau of Statistics. (2003). Measures of knowledge-based economy and society, Australia 2003 (No. 1377.0). Canberra, Australian Capital Territory: Australian Bureau of Statistics. Retrieved May 9, 2006, from AusStats database.

Australian Bureau of Statistics. (2005). Internet activity, Australia, March 2005 (No. 8153.0). Canberra, Australian Capital Territory: Australian Bureau of Statistics. Retrieved May 9, 2006, from AusStats database.

Campbell, G. (2005). There's something in the air: Podcasting in education. Educause Review, 40(6), 32-46. Retrieved January 11, 2006, from http://www.educause.edu/ir/library/pdf/erm0561.pdf.

Chan, A., \& Lee, M. J. W. (2005). An MP3 a day keeps the worries away: Exploring the use of podcasting to address preconceptions and alleviate pre-class anxiety amongst undergraduate information technology students. Paper presented at the 'Good practice in practice : proceedings of the Student Experience Conference 5-7th September '05' Wagga Wagga, NSW. Retrieved April 20, 2006, from A+ Education database.

Curtin University of Technology (2006, March 28, 2006). Curtin University Student Statistics 2005. Retrieved May 5, 2006, from http://planning.curtin.edu.au/stats/students2005.html

DeVoe, K. (2006). Innovations affecting us - podcasting, coursecasting, and the library. Against the Grain, 18(1), 78-79, 85.

Gordan-Murnane, L. (2005). Saying 'I do' to podcasting. Searcher, 13(6), 44-51. Retrieved May 5, 2006, from Proquest 5000 database.

Krätzig, G. P., \& Arbuthnott, K. D. (2006). Perceptual learning style and learning proficiency: A test of the hypothesis. Journal of Educational Psychology, 98(1), 238-246. Retrieved May 5, 2006, from Journals@Ovid database.

Lum, L. (2006). The power of podcasting. Diverse Issues in Higher Education, 23(2), 32-35. Retrieved April 26, 2006, from Proquest 5000 database.

Media and Publishing. (2006). Encyclopædia Britannica. Retrieved May 9, 2006, from Encyclopædia Britannica Online database. 
Rainie, L., \& Madden, M. (April 2005). Pew Internet \& American Life Project data memo: Podcasting. Retrieved May 5, 2005, from http://www.pewinternet.org/pdfs/PIP_podcasting.pdf 


\section{Appendix 1:}

\section{Curtin Library Podcasts}

O-week - February 202006 - Library Audio Tour

Are you new to Curtin University or just not sure where to find things in the Library? Download our Audio Tour and accompanying map and spend 20 minutes finding out about Curtin Library.

\section{Week 1 - February 272006 - ID Number and Password}

You probably know that your Curtin ID number and password will give you access to things like OASIS and WebCT or Blackboard, but did you know that your Curtin ID number and password will give you access to all kinds of useful stuff in the Library too?

\section{Week 2 - March 62006 - Borrowing}

This week, 5 useful tips on borrowing items from Curtin Library.

\section{Week 3 - March 132006 - Off Campus Library Services}

Are you studying externally and living more than $40 \mathrm{~km}$ from a Curtin campus? The library has extra services to help you get the resources you need - listen to this week's podcast to find out more!

\section{Week 4 - March 202006 - Ways to Contact Us}

Need help finding information or just want to make comment about the library? This week's podcast tells you the different ways you can contact us.

\section{Week 5 - March 272006 - Databases}

What are Library databases and why do you need them? Listen to this week's podcast to find out!

\section{Week 6 - April 32006 - Gecko}

Tips on using Gecko, the Library's database portal.

\section{Week 7 - April 112006 - Referencing}

Handy hints to help you with your referencing.

Week 8 - April 192006 - EndNote

Tips to get you started with EndNote.

\section{Week 9 - April 242006 - Web Searching}

Five effective internet search tips

\section{Week 10 - May 12006 - Frequently Asked Questions}

Did you know that you can borrow movies and novels from Curtin library? Listen in for these and more interesting tips! 


\section{Week 11 - May 82006 - Handy Reference Resources}

Tips for handy reference resources on the Curtin Library Webpage, from currency or measurement conversion tools to news sources, statistics and country information.

\section{Week 12 - May 152006 - Hansard, Bills and Acts}

During the course of your study you may find that you need to find and Act of Parliament or check a Regulation. This week's podcast outlines Bills, Acts and Hansard reports to give you and understanding of how they work.

\section{Week 13 - May 222006 - View-it Tutorials}

Don't have time to attend a library class, or forgotten some of the functions of EndNote? Why not use Curtin Library's View-it tutorials for a quick lesson.

\section{Week 14 - May 292006 - Exams}

Feeling stressed about your exams? Listen to this week's podcast for tips on how the library can help you prepare. 


\section{Appendix 2}

Usage Statistics for Semester One 2006

\begin{tabular}{|c|c|c|c|c|c|c|}
\hline $\begin{array}{c}\text { Semester } \\
\text { week }\end{array}$ & Podcast Title & February & March & April & May & Totals \\
\hline Orientation & Library Audio Tour & 91 & 111 & 89 & 86 & 377 \\
\hline 1 & $\begin{array}{l}\text { ID Number and } \\
\text { Password }\end{array}$ & 14 & 81 & 67 & 61 & 223 \\
\hline 2 & Borrowing & & 76 & 76 & 107 & 259 \\
\hline 3 & $\begin{array}{c}\text { Off Campus Library } \\
\text { Services }\end{array}$ & & 52 & 61 & 62 & 175 \\
\hline 4 & Ways to Contact Us & & 40 & 58 & 52 & 150 \\
\hline 5 & Databases & & 28 & 92 & 78 & 198 \\
\hline 6 & Gecko & & & 83 & 71 & 154 \\
\hline 7 & Referencing & & & 51 & 77 & 128 \\
\hline 8 & EndNote & & & 38 & 86 & 124 \\
\hline 9 & Web Searching & & & 40 & 75 & 115 \\
\hline 10 & $\begin{array}{c}\text { Frequently Asked } \\
\text { Questions }\end{array}$ & & & & 93 & 93 \\
\hline 11 & $\begin{array}{c}\text { Handy Reference } \\
\text { Resources }\end{array}$ & & & & 57 & 57 \\
\hline 12 & $\begin{array}{l}\text { Hansard, Bills and } \\
\text { Acts }\end{array}$ & & & & 40 & 40 \\
\hline 13 & View-It Tutorials & & & & 26 & 26 \\
\hline Totals & & 105 & 388 & 655 & 971 & 2119 \\
\hline
\end{tabular}

